\title{
Oral impacts on the daily performance of Brazilians assessed using a sociodental approach: analyses of national data
}

Rosana Leal do PRADO Nemre Adas SALIBA Cléa Adas Saliba GARBIN Suzely Adas Saliba MOIMAZ

Univ. Estadual Paulista - Unesp, Faculdade de Odontologia, Preventive and Social Dentistry Graduate Program, Araçatuba, SP, Brazil.

Declaration of Interests: The authors certify that they have no commercial or associative interest that represents a conflict of interest in connection with the manuscript.

Corresponding Author:

Rosana Leal do Prado

E-mail: rosanahb@yahoo.com.br

DOI: 10.1590/1807-3107BOR-2015.vol29.0086

Submitted: Oct 06, 2014

Accepted for publication: Mar 10, 2015

Last revision: Jun 01, 2015
Abstract: The aim of this study was to analyze the relationship between oral diseases and their impact on the daily performance of adult and elderly Brazilians, verify the association of oral diseases with socioeconomic and demographic features, and compare the standard estimate of need with the sociodental assessment of these same needs. The authors evaluated data from 17,398 Brazilians aged between 35-44 years and 65-74 years, taken from the cross-sectional Brazilian Oral Health Survey (Saúde Bucal Brasil - SBBrasil). Regression models were applied to assess associations among impacts on daily performance and income, schooling, gender, region, use of dental services, health perception and dental disease status. McNemar's test was applied to compare standard versus impact-related estimates of need. The prevalence ratio of these impacts was associated with the sociodemographic versus health perceptions $(p<0.001)$ of adults and the elderly. Adults also had impacts associated with loss of periodontal attachment ( $p<0.001)$. The prevalence of normative needs was $95.39 \%$ for adults and $99.76 \%$ for the elderly, whereas the impact-related estimate of need was $50.92 \%$ and $43.71 \%$, respectively. The impacted-related approach had a statistically significant association with the normative estimate of need $(p<0.001)$. This study showed a relationship between oral impact on daily performance of adults and educational level. Sociodemographic features were also related to the impacts on both adults and the elderly, and to health perception. The impacts among the adults were related to the loss of periodontal attachment. In addition, the authors found a sizable difference between the standard versus the sociodental approach, in that the sociodental assessment needs were lower than the needs identified by the standard estimate of need.

Keywords: Oral Health; Quality of Life; Needs Assessment; Health Inequalities.

\section{Introduction}

Oral health has been increasingly recognized as a factor that affects the quality of life of individuals. Negative impacts on oral health adversely influence people's daily performance. ${ }^{1}$ 
Oral diseases not only cause pain, but may also lead to social embarrassment and trigger processes of suffering, making the whole body suffer. ${ }^{2}$ The World Health Organization indicates that oral health is essential to promote general health and quality of life. It characterizes oral health as "being free from mouth and facial pain, oral and throat cancer, oral infection and sores, periodontal (gum) disease, tooth decay, tooth loss, and other diseases and disorders that limit an individual's capacity in biting, chewing, smiling, speaking, and psychosocial wellbeing". ${ }^{3}$

However, throughout its history, dentistry has maintained the almost exclusive use of clinical indicators, dependent on professional judgment to assess the health of individuals and plan oral health actions. ${ }^{4}$ This approach may underestimate the relationship that other factors have on health, hinder the construction of a dynamic overview of how oral conditions affect people's lives, ${ }^{5}$ and jeopardize the rational workforce organization in the meeting of population needs. ${ }^{6}$

Thus, the exclusive use of normative approaches may be counter-intuitive, since the health-disease binomial has been understood as the result of several factors, ranging from subjective and individually unique to factors related to the social determinants of health. ${ }^{78,9}$ Among these determinants, socioeconomic and demographic characteristics may affect oral health and consequently the quality of life. ${ }^{10}$

The major shortcoming of the normative approach is that this falls short of assessing how people really feel, and this produces a narrowing of the broader understanding of health and needs. ${ }^{5,11}$

Although a fifth of all the dentists in the world are in Brazil ${ }^{12}$ there have not been many advances in approaches other than the normative approach, and oral problems persist in impacting people's lives, ${ }^{13}$ not to mention the difficulty of organizing the health system to effectively meet people's demands. Despite this large number of professionals, access to dental care is not equitable. About $60 \%$ of all Brazilian dentists work in only 4 states, all located in the southeastern region, the richest of the nation, home to major cities like Rio de Janeiro and Sao Paulo. ${ }^{12}$ In the last national oral survey, $14.5 \%$ of adult and $28.5 \%$ of elderly Brazilians never visited the dentist. ${ }^{13}$
In an effort to bridge these gaps, indicators of sociodental approach have been developed and may contribute to clinical decision-making and to organizing demand, insofar as they are guided by measures of quality of life and allow better assessment of oral health. Measures relating to the impact of oral health on daily activities should be established for conditions resulting from non-treatment and not causing serious damage to health, and should not be used as a substitute but rather as a complement to clinical measures. ${ }^{5}$ In a theoretical model, the first step entails the identification of normative needs, establishing if dental diseases are likely to progress or require emergency treatment. If either of these situations is confirmed, clinical treatment is imminently necessary, leaving only the issue of what the best clinical course would be. In other situations, the procedure is to identify the needs related to the impact by way of subjective indicators; in this case, people would be assigned to two groups, those who suffer from some impact on daily life, and those who receive no such impact. The related need should be dealt with on a third level of assessment, which considers the individual behavior of each person. As such, it focuses on the probability of success by proposing a more appropriate treatment, according the person's real needs. ${ }^{11}$ In Brazil, the study of a social dental approach remains incipient, and the manner in which people's lives are affected by oral health requires greater investigation. ${ }^{14}$

Thus, the aim of this study was to analyze the relationship between oral diseases and their impact on the daily performance of adult and elderly Brazilians, verify the association of these diseases with socioeconomic and demographic features, and compare standard estimate of need with sociodental assessment.

\section{Methodology}

We performed a cross-sectional secondary analysis of data from a national oral health survey carried out by the Ministério da Saúde (Brazilian Health Ministry) in 2010, called "SBBrasil 2010". The study population was assessed according to the World Health Organization directions for Epidemiologic Surveys. ${ }^{15}$ The survey sample selected people in all of Brazil's 27 states. Physical examinations were performed at 
the household of the surveyed population in order to evaluate the oral health status of five different age groups, ranging from children to elderly people, comprising a total of 37,519 people. A questionnaire was used to identify socioeconomic features and the impacts of oral health on daily life. The details on the methodology for data collection of the national survey are available in the literature. ${ }^{16}$

Our study included data from adults (35-44 years old) and the elderly (65-74 years old) $(n=17,398)$ on periodontal disease, tooth loss, treatment needs, oral impacts on daily performance (Oral Impacts on Daily Performance-OIDP), socioeconomic and demographic characteristics, health-related perception, and use of dental services. The dependent variable was the Oral Health-Related Quality of Life (OHRQoL), measured by OIDP. Individuals were asked different questions related to the period six months preceding the survey. These included whether they had an oral problem that caused difficulties eating and enjoying food, speaking, brushing their teeth, sleeping and relaxing, smiling, giggling and showing their teeth without being ashamed, whether they maintained a balanced emotional state without getting angry, whether they played a leading or a social role, and whether they had contact with people. The possible answers were a dichotomous yes or no. ${ }^{13}$ The questions evaluated people's performance in three different domains: physical, psychological and social. ${ }^{1}$ The people who had reported at least one complaint were assigned to the group, "Presence of interference in daily life", whereas the people who had no complaints were assigned to the group, "Absence of interference in daily life".

The impact-related estimate of need was measured by the prevalence of people who reported any interference of oral health in daily performance and also had a normative estimate of need. This variable was calculated for each of the four clinical conditions.

The analyses were carried out based on the hierarchic model proposed by Dahlgren and Whitehead ${ }^{17}$ and adapted for this study, in which the explanatory variables were grouped into five blocks where demographic characteristics were seen as proximal determinants, and had an influence on the other determinants. The first block, "Demographic features", contained the variables of gender, region of residence and ethnicity. The second was "Socioeconomic features", and included the variables of reported monthly household income in Brazilian reais (BRL) and education in years. Income was categorized as: up to $500 \mathrm{BRL}, 501$ to $1500 \mathrm{BRL}$, 1501 to 4500 BRL and over 4500 BRL. Education was categorized as less than 8 years, between $9-11$ years and 12-15 years. The third block was "Oral health perception" and the variables in this group were tooth pain (presence or absence), oral health satisfaction (Very High/High, Regular/Low/Very Low), and related need for dental prostheses. The fourth block was "Use of dental services" and was composed only of the variable: last dental visit (less than one year ago, more than 1 year ago). The last block was called the "Standard normative estimate of need". The variables in this group consisted of: Presence of bleeding on probing/calculus, obtained from the Community Periodontal Index (CPI), Tooth loss (people who had at least 1 missing tooth) and Dental prosthodontic need.

The analysis took into account the complex structure of the cluster sample and the sample weights, ${ }_{1}^{18}$ using the survey commands in the Stata software, 11.2 version (Stata Corp., College Station, USA).

The association between different socioeconomic and demographic aspects and impact on daily life were analyzed by the Poisson Regression, using robust variance and determining the prevalence ratio. In selecting the explanatory variables used for adjusting the Poisson Regression, the inclusion criteria were the relationship between the explanatory variable and the outcome variable in the univariate analysis, with the significance level set at $25 \%{ }^{19}$ The variables above this cut-off point were not included. In this analysis, the authors also estimated the crude prevalence ratio with $95 \%$ confidence intervals in a forward selection. The significance level was set at $p<0.05$ in order to keep the variables in the final model. The authors compared both the standard and the impact-related estimates of need using McNemar's test, with a significance level of $\mathrm{p}<0.05$.

\section{Results}

Of the 17,398 participants, 9779 (56.2\%) were adults and 7619 (43.8\%) were elderly. Of the adults, 6405 
- Oral impacts on the daily performance of Brazilians assessed using a sociodental approach: analyses of national data

(65.5\%) were female and 3374 (34.5\%) were male. In regard to the elderly, $4716(61.9 \%)$ were women and 2903 (38.1\%) were men (Table 1).

Table 1 shows the univariate analyses with the respective $p$-values and prevalence for each explanatory variable included in the analyses.

In regard to the adults, women had a higher prevalence of impacts compared with men (Table 2). All of the non-white ethnic groups, among the adults and the elderly, had a higher prevalence of impacts on daily life, as compared with the white ethnic group (Tables 2 and 3). The prevalence of oral health interference in a person's routine was $43 \%$ higher among less educated adults, whereas income had no statistically significant association between the white and the non-white groups (Tables 2 and 3).

Oral health interference in quality of life was more prevalent among people who reported dissatisfaction,

Table 1. Univariate Poisson Regression for Oral Impact on Daily Life of Adult and Elderly Brazilians - Brazil, 2014.

\begin{tabular}{|c|c|c|c|c|c|c|}
\hline \multirow{2}{*}{ Variable } & \multicolumn{3}{|c|}{ Adults } & \multicolumn{3}{|c|}{ Elderly } \\
\hline & $\mathrm{n}$ & $\%$ & $\mathrm{p}$-value & $\mathrm{n}$ & $\%$ & $\mathrm{p}$-value \\
\hline \multicolumn{7}{|l|}{ Sociodemographic features } \\
\hline \multicolumn{7}{|l|}{ Gender } \\
\hline Male & 3374 & 34.50 & 0.046 & 2903 & 38.10 & 0.579 \\
\hline Female & 6405 & 65.50 & & 4716 & 61.90 & \\
\hline \multicolumn{7}{|l|}{ Ethnicity } \\
\hline White & 4137 & 42.30 & $<0.001$ & 3577 & 46.95 & 0.168 \\
\hline Black & 1020 & 10.43 & & 879 & 11.54 & \\
\hline Brown & 4386 & 44.85 & & 2970 & 38.98 & \\
\hline Other & 236 & 2.42 & & 193 & 2.53 & \\
\hline \multicolumn{7}{|l|}{ Region of residence } \\
\hline Southeast & 2585 & 26.43 & 0.147 & 1758 & 23.07 & 0.328 \\
\hline South & 2456 & 25.12 & & 2294 & 30.11 & \\
\hline Midwest & 1608 & 16.44 & & 1287 & 16.89 & \\
\hline Northeast & 1638 & 16.75 & & 1163 & 15.26 & \\
\hline North & 1492 & 15.26 & & 1117 & 14.66 & \\
\hline \multicolumn{7}{|l|}{ Socioeconomic features } \\
\hline \multicolumn{7}{|l|}{ Monthly income (in BRL) } \\
\hline Up to 500 & 1420 & 14.89 & $<0.001$ & 849 & 11.57 & 0.339 \\
\hline Between 501-1500 & 4783 & 50.16 & & 4029 & 54.91 & \\
\hline Between 1501-4500 & 2813 & 29.50 & & 1999 & 27.24 & \\
\hline Over 4500 & 519 & 5.45 & & 461 & 6.28 & \\
\hline \multicolumn{7}{|l|}{ Schooling } \\
\hline Up to 8 years & 4371 & 45.09 & $<0.001$ & 5813 & 78.34 & 0.2464 \\
\hline $9-11$ years & 3025 & 31.21 & & 870 & 11.72 & \\
\hline $12-15$ years & 2297 & 23.70 & & 738 & 9.94 & \\
\hline \multicolumn{7}{|l|}{ Health perception } \\
\hline \multicolumn{7}{|l|}{ Oral health satisfaction } \\
\hline Yes & 5684 & 58.12 & $<0.001$ & 5220 & 68.51 & $<0.001$ \\
\hline No & 4095 & 41.88 & & 2399 & 31.49 & \\
\hline \multicolumn{7}{|l|}{ Tooth pain } \\
\hline Yes & 2366 & 24.42 & $<0.001$ & 791 & 11.07 & $<0.001$ \\
\hline No & 7324 & 75.58 & & 6354 & 88.93 & \\
\hline
\end{tabular}

Continue 


\begin{tabular}{|c|c|c|c|c|c|c|}
\hline \multicolumn{7}{|l|}{ Continuation } \\
\hline \multicolumn{7}{|l|}{ Perceived prosthesis need } \\
\hline Yes & 3958 & 41.79 & $<0.001$ & 4237 & 56.96 & $<0.001$ \\
\hline No & 5514 & 58.21 & & 3202 & 43.04 & \\
\hline \multicolumn{7}{|l|}{ Use of dental services } \\
\hline \multicolumn{7}{|l|}{ Last dental appointment } \\
\hline Less than one year ago & 4543 & 51.03 & 0.194 & 2041 & 33,73 & 0.879 \\
\hline More than one year ago & 4360 & 49.97 & & 4010 & 66.27 & \\
\hline \multicolumn{7}{|l|}{ Normative needs } \\
\hline \multicolumn{7}{|c|}{ Bleeding on probing/dental calculus } \\
\hline Yes & 5859 & 78.45 & $<0.001$ & 2032 & 92.62 & $<0.001$ \\
\hline No & 1609 & 21.55 & & 162 & 7.38 & \\
\hline \multicolumn{7}{|c|}{ Loss of periodontal attachment } \\
\hline Yes & 4448 & 50.24 & $<0.001$ & 6649 & 95.14 & 0.014 \\
\hline No & 4406 & 49.76 & & 340 & 4.86 & \\
\hline \multicolumn{7}{|l|}{ Tooth loss } \\
\hline Yes & 7928 & 85.35 & 0.002 & 3726 & 96.06 & 0.001 \\
\hline No & 1361 & 14.65 & & 153 & 3.94 & \\
\hline \multicolumn{7}{|l|}{ Edentulousness } \\
\hline Yes & 270 & 2.82 & 0.993 & 3583 & 47.72 & 0.726 \\
\hline No & 9294 & 97.18 & & 3926 & 52.28 & \\
\hline
\end{tabular}

dental pain and the need for prostheses (Tables 2 and 3 ). In assessing the normative measures, adults with loss of periodontal attachment had a higher prevalence of impacts on daily life (Table 2).

In the elderly group, there was no statistically significant association between the oral health impacts on daily life and the standard normative estimate of need after adjustment for other covariates. However, among the seniors, the prevalence of impacts was $65 \%$ higher for those dissatisfied with their oral health than for those who reported being very satisfied/satisfied (Table 3).

Overall, the authors found the prevalence of normative needs for any of the aforementioned dental conditions to be $95.39 \%$ among adults and $99.76 \%$ among the elderly (Table 4). The prevalence of the standard normative estimate of need was significantly different from the impact-related need, which was lower for all of the four dental conditions, for both age ranges $(p<0.001)$. The global prevalence of oral impacts on daily performance was $50.92 \%(n=5058)$ for adults and $43.71 \%(n=3313)$ for seniors. The prevalence of standard versus sociodental estimates of need for treatment of bleeding on probing in adults was $59.80 \%$ versus $32.84 \%$, respectively; in the elderly it was $26.63 \%$ versus $12.84 \%$. The respective prevalence for tooth loss was $80.93 \%$ versus $44.48 \%$ among adults, and $48.79 \%$ versus $23.13 \%$ for the elderly (Table 4 ).

\section{Discussion}

This study showed the prevalence of oral health impacts on daily life among adult and elderly Brazilians. Our findings indicated the influence of a poor education on the daily life impacts of adults. Although the univariate analysis showed an association between adults and the elderly in regard to income, this trend was not confirmed in the final models, in disagreement with other studies. ${ }^{10,20}$ Our findings agree with the results by Pereira et al. ${ }^{21}$ who did not find a statistically significant association between daily impacts and education level of the elderly, whereas the study by Gomes et al..$^{22}$ reported no association of impacts with the income of adults. Both studies were developed in southern Brazil.

As a strategy to act on the social determinants of health, Brazil has been recognized internationally for its Bolsa Família [Family Allowance] Program, consisting of granting cash transfers to families in extreme poverty. After the initiative was launched in 2003, it reduced the inequality in the country, particularly regarding key aspects such as education and health. ${ }^{23}$ 
- Oral impacts on the daily performance of Brazilians assessed using a sociodental approach: analyses of national data

Table 2. Final Poisson Regression Model for Oral Impact on the Daily Life of Adult Brazilians between 35-44 years old - Brazil, 2014.

\begin{tabular}{|c|c|c|c|c|c|}
\hline Variables & $\mathrm{PR}_{c}$ & $\mathrm{PR}_{\mathrm{a}}$ & $\mathrm{Cl} 95 \% \mathrm{PR}_{a}$ & $\mathrm{p}^{\dagger}$ & $p^{\ddagger}$ \\
\hline \multicolumn{6}{|l|}{ Sociodemographic features } \\
\hline \multicolumn{6}{|l|}{ Gender } \\
\hline Male & 1 & 1 & - & - & $<0.001$ \\
\hline Female & 1.15 & 1.15 & $1.01-1.30$ & 0.032 & \\
\hline \multicolumn{6}{|l|}{ Ethnicity } \\
\hline White & 1 & 1 & - & & \\
\hline Black & 1.17 & 1.17 & $1.04-1.33$ & 0.012 & \\
\hline Brown & 1.21 & 1.22 & $1.11-1.34$ & $<0.001$ & \\
\hline Other & 1.23 & 1.25 & $1.00-1.55$ & 0.043 & \\
\hline \multicolumn{6}{|l|}{ Region of residence } \\
\hline Southeast & 1 & 1 & - & - & \\
\hline South & 1.09 & 1.07 & $0.94-1.23$ & 0.301 & \\
\hline Midwest & 1.20 & 1.24 & $1.05-1.46$ & 0.010 & \\
\hline Northeast & 1.02 & 1.12 & $0.95-1.32$ & 0.166 & \\
\hline North & 1.13 & 1.15 & $0.94-1.40$ & 0.164 & \\
\hline \multicolumn{6}{|l|}{ Socioeconomic features* } \\
\hline \multicolumn{6}{|l|}{ Monthly income (in BRL) } \\
\hline Up to 500 & 1.48 & 1.12 & $0.78-1.60$ & 0.294 & $<0.001$ \\
\hline Between 501-1500 & 1.26 & 0.98 & $0.68-1.42$ & 0.927 & \\
\hline Between 1501-4500 & 0.95 & 0.83 & $0.59-1.17$ & 0.544 & \\
\hline Over 4500 & 1 & 1 & - & - & \\
\hline \multicolumn{6}{|l|}{ Schooling } \\
\hline Up to 8 years & 1.56 & 1.43 & $1.12-1.82$ & 0.004 & \\
\hline $9-11$ years & 1.25 & 1.18 & $0.96-1.47$ & 0.109 & \\
\hline $12-15$ years & 1 & 1 & - & - & \\
\hline \multicolumn{6}{|l|}{ Health perception** } \\
\hline \multicolumn{6}{|l|}{ Oral health satisfaction } \\
\hline Yes & 1 & 1 & - & & $<0.001$ \\
\hline No & 1.88 & 1.58 & $1.45-1.72$ & $<0.001$ & \\
\hline \multicolumn{6}{|l|}{ Tooth pain } \\
\hline Yes & 1.74 & 1.50 & $1.39-1.63$ & $<0.001$ & \\
\hline No & 1 & 1 & & & \\
\hline \multicolumn{6}{|l|}{ Perceived prosthesis need } \\
\hline Yes & 1.47 & 1.23 & $1.14-1.31$ & $<0.001$ & \\
\hline No & 1 & 1 & - & & \\
\hline \multicolumn{6}{|l|}{ Normative needs $* * *$} \\
\hline Loss of periodontal attachment & & & & & $<0.001$ \\
\hline Yes & 1.37 & 1.14 & $1.01-1.31$ & $<0.001$ & \\
\hline No & 1 & 1 & - & & \\
\hline
\end{tabular}

PRc: Crude prevalence ratio; $\mathrm{OR}_{\mathrm{a}}$ : Adjusted prevalence ratio; $\mathrm{p}^{\dagger}$ : category $\mathrm{p}$-value; $\mathrm{p}^{\ddagger}$ : variable $\mathrm{p}$-value; BRL: Brazilian Reais - 1 American dollar $=1.66$ Brazilian reais at the time of the survey.

*Adjusted by gender, ethnicity, region of residence.

**Adjusted by gender, ethnicity, region of residence, monthly income, schooling.

***Adjusted by gender, ethnicity, region of residence, monthly income, schooling, oral health satisfaction, tooth pain and perceived need for prostheses.

The authors also found a statistically significant association among oral health impacts, ethnicity, and region of residence. These relationships could be related to the nation's income concentration, which is historically greater in the South and Southeast, the latter of which is home to Brazil's major cities, like 
Table 3. Final Poisson Regression Model for Oral Impact on the Daily Life of Elderly Brazilians between 65-74 years old - Brazil, 2014.

\begin{tabular}{|c|c|c|c|c|c|}
\hline Variables & $\mathrm{PR}_{\mathrm{c}}$ & $\mathrm{PR}_{\mathrm{a}}$ & $\mathrm{Cl} 95 \% \mathrm{PR}_{\mathrm{a}}$ & $p^{\dagger}$ & $p^{\ddagger}$ \\
\hline \multicolumn{6}{|l|}{ Sociodemographic features } \\
\hline \multicolumn{6}{|l|}{ Ethnicity } \\
\hline White & 1 & 1 & - & - & \\
\hline Black & 1.09 & 1.09 & $0.91-1.31$ & 0.332 & \\
\hline Brown & 1.13 & 1.13 & $0.99-1.30$ & 0.071 & 0.1677 \\
\hline Other & 0.90 & 0.90 & $0.59-1.37$ & 0.613 & \\
\hline \multicolumn{6}{|l|}{ Socioeconomic features* } \\
\hline \multicolumn{6}{|l|}{ Schooling } \\
\hline Up to 8 years & 1.13 & 1.10 & $0.81-1.51$ & 0.663 & \\
\hline 9-11 years & 0.94 & 0.91 & $0.63-1.34$ & 0.541 & 0.2520 \\
\hline $12-15$ years & 1 & 1 & - & - & \\
\hline \multicolumn{6}{|l|}{ Health perception** } \\
\hline \multicolumn{6}{|l|}{ Oral health satisfaction } \\
\hline Yes & 1 & 1 & - & - & \\
\hline No & 2.06 & 1.65 & $1.46-1.87$ & $<0.001$ & \\
\hline \multicolumn{6}{|l|}{ Tooth pain } \\
\hline Yes & 1.77 & 1.65 & $1.39-1.95$ & $<0.001$ & \\
\hline No & 1 & - & - & & $<0.001$ \\
\hline \multicolumn{6}{|l|}{ Perceived prostheses need } \\
\hline Yes & 2.07 & 1.64 & $1.37-1.98$ & $<0.001$ & \\
\hline No & 1 & - & - & & \\
\hline
\end{tabular}

PRc: Crude prevalence ratio; $\mathrm{OR}_{\mathrm{a}}$ : Adjusted prevalence ratio; $\mathrm{p}^{\dagger}$ : category $\mathrm{p}$-value; $\mathrm{p}^{\ddagger}$ : variable $\mathrm{p}$-value; BRL: Brazilian Reais - 1 American dollar $=1.66$ Brazilian reais at the time of the survey.

*Adjusted by ethnicity.

**Adjusted by ethnicity and schooling.

Table 4. Standard Normative and Impact-Related Estimate of Need by Adult and Elderly Brazilians - Brazil, 2014.

\begin{tabular}{|c|c|c|}
\hline \multirow{2}{*}{ Dental Condition } & \multicolumn{2}{|c|}{ Prevalence } \\
\hline & Standard normative estimate of need (\%) & Impact-related (sociodental) estimate of need (\%) \\
\hline \multicolumn{3}{|l|}{ Adults (35-44 years old) } \\
\hline Bleeding on probing & 59.80 & $32.84^{a}$ \\
\hline Tooth Loss & 80.93 & $44.84^{\circ}$ \\
\hline Edentulousness & 2.75 & $1.28^{\circ}$ \\
\hline Prosthodontic need & 75.65 & $43.38^{\circ}$ \\
\hline Any of these four dental conditions & 95.39 & $50.92^{a}$ \\
\hline \multicolumn{3}{|l|}{ Elderly (65-74 years old) } \\
\hline Bleeding on probing & 26.63 & $12.84^{a}$ \\
\hline Tooth Loss & 48.79 & $23.13^{a}$ \\
\hline Edentulousness & 46.65 & $18.53^{\circ}$ \\
\hline Prosthodontic need & 95.52 & $42.67^{\circ}$ \\
\hline Any of these four dental conditions & 99.76 & $43.71^{\mathrm{a}}$ \\
\hline
\end{tabular}

${ }^{a} p<0.001$ - Comparison between impacted-related (sociodental) assessed need and standard normative assessment of need (normative need) (McNemar's test) 
Sao Paulo and Rio de Janeiro, which contain a major part of the self-declared white Brazilian population, and which amass the highest income.

Health perception was related to the presence of impacts. Adults and elderly people who associated dissatisfaction with oral health, tooth pain and need for dental prostheses had a higher prevalence of interference in daily life. Rosenoer and Sheiham ${ }^{24}$ reported a very weak association between satisfaction with teeth and number of missing teeth. In their study, satisfaction was age-related and older people were more satisfied than younger people.

The unmet needs measured by the normative approach indicated a statistically significant association with the impacts on the daily life of adults. ${ }^{25,26}$ This was not the case in regard to people between 65-74 years old. This lack of association could be explained by the psychological aging process itself, or even by the belief of an association between old age and the inevitable loss of teeth, together with the consequent need for dentures. ${ }^{21}$ In contrast, Sheiham et al..$^{27}$ found that the oral status of older people frequently affects the quality of life of older people, in particular, their ability to eat several common types of food. Nevertheless, in their study edentulous people did not present impacts that could be related with our study, since almost half of the elderly from the SBBrasil sample had no teeth.

The prevalence of impacts on adults was found to be lower in this study (50.92\%) than the prevalence rate of $82.6 \%{ }^{28}$ reported by Mohebbi et al. ${ }^{28}$ on the adults attending a university dental clinic in Iran. However, the prevalence of impacts among the elderly (43.71\%) participating in this study was very similar to that reported by Pereira et al. ${ }^{21}$ in a study carried out in Florianópolis, southern Brazil.

When an impacted-related approach was used to estimate the oral health needs of adult and elderly Brazilians, the authors of the present study found a significant decrease in the prevalence rate compared with the normative estimate of need. Similar findings were reported in studies carried out in South Korea ${ }^{6}$ and Thailand, ${ }^{29}$ and should be underscored, since they could reduce the estimated cost of treatment need and help organize the dental care health system. High levels of normative treatment needs are common, because they do not take into account a person's perception of need or other related elements that could influence treatment needs. ${ }^{29}$ Welfare policies for health, especially in a large country such as Brazil, should take into account other approaches other than those used traditionally to organize dental care access, since the professional assessment of needs may overestimate actual oral health treatment needs. The current study has the advantages of using data from a large national sample of adult and elderly Brazilians, taken from a government survey sponsored by the Brazilian Ministry of Health, which represents the first nationwide oral survey carried out in households. Data collection using a sociodental approach can also help better organize dental care access to public health services. However, considering the cross-sectional nature of the study, relative hypotheses can be suggested, but no causal inferences can be concluded from this study. It is important to bear in mind that the examiners called to conduct the clinical examinations were calibrated according to World Health Organization criteria. ${ }^{13}$ Nevertheless, the normative needs variable was established as stated in the methods section, and represents a secondary measure. Owing to the large sample size, type II error was heightened and association tests could be jeopardized. Additionally, the dataset lacked important data about individual behaviors and general health characteristics or habits, such as drinking and smoking. In addition, there was no detailed scoring of severity and frequency of oral impact in daily performance measures. This could have provided the study with greater precision.

\section{Conclusion}

This study showed a relationship between oral impact on daily performance of adults and educational level. Sociodemographic features were also related to the impacts on both groups, as well as to health perception. Among the adults, the impacts were related to the loss of periodontal attachment. In addition, we found that there was a large difference between the standard and the sociodental approaches, in that the sociodental assessment needs were lower than those identified by the standard estimate of need. 


\section{References}

1. Gomes AS, Abegg C. The impact of oral health on daily performance of municipal waste disposal workers in Porto Alegre, Rio Grande do Sul State, Brazil. Cad Saude Publica. 2007 Jul;23(7):1707-14. Portuguese.

2. Sheiham A. Oral Health, General Health and Quality of Life. Bull World Health Organ. 2005 Sep;83(9):644.

3. World Health Organization. Report on Oral Health. Fact Sheet \#318. 2012. [cited 2014 Oct 2]. Available from: http://www.who.int/mediacentre/factsheets/fs318/en/

4. Asgari I, Ahmady AE, Yadegarfar G, Eslamipour F. Evaluation of orthodontic treatment need by patient-based methods compared with normative method. Dent Res J. 2013 Sep;10(5):636-42.

5. Gherunpong S, Sheiham A, Tsakos G. A sociodental approach to assessing children's oral health needs: integrating an oral health-related quality of life (OHRQoL) measure into oral health service planning. Bull World Health Organ. 2006 Jan;84(1):36-42.

6. Ryu JI, Tsakos G, Sheiham A. Differences in prosthodontic treatment needs assessments between the standard normative and sociodental approach. Int J Prosthodont. 2008 Sep-Oct;21(5):425-32.

7. Marmot M, Bell R. Social determinants and dental health. Adv Dent Res. 2011 May;23(2):201-6.

8. Marmot M, Bell R. Fair society, healthy lives. Public Health. 2012 Sep;126 Suppl 1:S4-S10.

9. Sabbah W, Tsakos G, Chandola T, Newton T, Kawachi I, Sheiham A, et al. The relationship between social network, social support and periodontal disease among older Americans. J Clin Periodontol. 2011;38(6):547-52.

10. Pistorius J, Horn JG, Pistorius A, Kraft J. Oral health-related quality of life in patients with removable dentures. Schweizer Monatsschrift fur Zahnmedizin. 2013;123(11):964-71; 55.

11. Sheiham A, Tsakos G. Avaliando necessidades através de abordagem sócio-odontológica. In: Pinto VG, editor. Saúde Bucal Coletiva. 5th ed. [place unknown]: Ed. Santos; 2008. p. 287-316.

12. Morita MC. Perfil Atual e tendências do cirurgião-dentista brasileiro. 1st ed. Maringá: Dental Press; 2010. 96 p.

13. Brasil. Ministério da Saúde. Secretaria de Atenção à Saúde. Secretaria de Vigilância em Saúde. Departamento de Atenção Básica. Coordenação Nacional de Saúde Bucal da População Brasileira. SB Brasil 2010: pesquisa nacional de saúde bucal - resultados principais. Brasília (DF): Ministério da Saúde; 2011 [cited 2014 Oct 02]. Available from: http://189.28.128.100/ dab/docs/geral/projeto_sb2010_relatorio_final.pdf dab/docs/geral/projeto_sb2010_relatorio_final.pdf National Oral Health Survey - SBBrasil

14. Jahnke MM, Ponte ME, Abegg C, Fontanive VN, Davoglio R. Self-perceived and normative need for dental treatment of individuals from three health districts of Porto Alegre, RS, Brazil. RFO UPF 2013;18(3):271-6. Portuguese.
15. World Health Organization. Oral Health Surveys - Basic Methods. 4th ed. Geneva: PAHO/WHO; 1997. 66 p.

16. Roncalli AG, Silva NN, Nascimento AC, Freitas CH, Casotti E, Peres KG, et al. Relevant methodological issues from the SBBrasil 2010 Project for national health surveys. Cad Saude Publica. 2012;28 Suppl:s40-57. Portuguese.

17. Dahlgren GE, Whitehead M. European strategies for tackling social inequities in health: Levelling up Part 2. Denmark: WHO Collaborating Centre for Policy Research on Social Determinants of Health University of Liverpool; 2007.

18. Silva NN, Roncalli AG. Plano amostral, ponderação e efeitos do delineamento da Pesquisa Nacional de Saúde Bucal. Rev Saude Publica. 2013 Dec;47 Suppl 3:3-11.

19. Hosmer D, Lemeshow S, Sturdivant R. Applied logistic regression. 3rd ed. New York: John Wiley \& Sons; 2013. 528 p.

20. Lacerda JT, Castilho EA, Calvo MC, Freitas SF. Oral health and daily performance in adults in Chapeco, Santa Catarina State, Brazil. Cad Saude Publica. 2008 Aug;24(8):1846-58. Portuguese.

21. Pereira KC, Lacerda JT, Traebert J. The oral impact on daily performances and self-reported quality of life in elderly people in Florianopolis, Brazil. Oral Health Prev Dent. 2009;7(2):163-72.

22. Gomes AS, Abegg C, Fachel JM. Relationship between oral clinical conditions and daily performances. Braz Oral Res. 2009 Jan-Mar;23(1):76-81.

23. Marmot M, Commission on Social Determinants of $\mathrm{H}$. Achieving health equity: from root causes to fair outcomes. Lancet. 2007 Sep;370(9593):1153-63.

24. Rosenoer LM, Sheiham A. Dental impacts on daily life and satisfaction with teeth in relation to dental status in adults. J Oral Rehabil. 1995 Jul;22(7):469-80.

25. Zeng X, Sheiham A, Bernabe E, Tsakos G. Relationship between dental status and Oral Impacts on Daily Performances in older Southern Chinese people. J Public Health Dent. 2010 Spring;70(2):101-7.

26. Tsakos G, Marcenes W, Sheiham A. The relationship between clinical dental status and oral impacts in an elderlySheiham A, Steele JG, Marcenes W, Tsakos G, Finch S, Walls AW. Prevalence of impacts of dental and oral disorders and their effects on eating among older people; a national survey in Great Britain. Community Dent Oral Epidemiol. 2001 Jun;29(3):195-203.

27. Mohebbi SZ, Sheikhzadeh S, Batebi A, Bassir SH. Oral Impacts on Daily Performance in 20- to 50-yearolds Demanding Dental Care in Tehran, Iran: Association with Clinical Findings and Self-reported Health. Oral Health Prev Dent. 2014;12(1):29-36.

28. Srisilapanan P, Korwanich N, Sheiham A. Assessing prosthodontic dental treatment needs in older adults in Thailand: normative vs. sociodental approaches. Spec Care Dentist. 2003 Jul-Aug;23(4):131-4. 